\title{
Remophilanetriol: A New Eremophilane from the Roots of Rehmannia glutinosa
}

\author{
Hyuncheol Oh \\ MCBI \& College of Natural Sciences, Silla University, Busan 617-736, Korea. E-mail: hoh@silla.ac.kr \\ Received May 24, 2005
}

Key Words : Rehmannia glutinosa, Eremophilane, Natural product, Structure determination, NMR

Radix Rehmanniae is the fresh or dry root of Rehmannia glutinosa Libosch. (Scrophulariiaceae), and is traditionally used for antipyretic and hemostatic. The roots of Rehmannia glutinosa have been also used as a tonic and sedative after processing of the fresh root such as boiling in the rice wine or steaming. ${ }^{1}$ A number of constituents such as iridoids, ${ }^{2-4}$ phenethyl alcohol glycosides, ${ }^{5,6}$ glycosides, ${ }^{7}$ cyclopentanoid monoterpenes, ${ }^{8}$ and norcarotenoids, ${ }^{9}$ have been reported from the fresh or processed roots of $R$. glutinosa. In the course of chemical investigation on the dried roots of $R$. glutinosa, a new eremophilane-type metabolite, named remophilanetriol (1), was encountered, together with aeginetic acid (2), which has been identified from the same species. ${ }^{9}$ Details of the isolation and structure elucidation of new compound (1) are described in the present study.

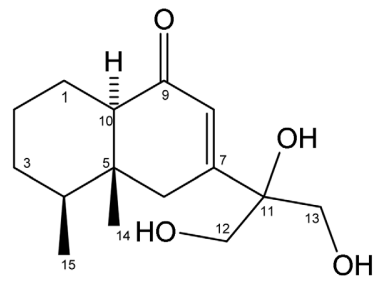

1

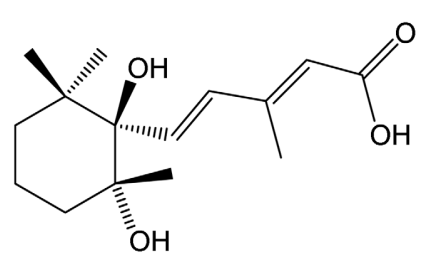

2
The MeOH extract of Rehmannia glutinosa was concentrated, suspended in $\mathrm{H}_{2} \mathrm{O}$, and sequentially partitioned with $n$-hexane, EtOAc, and BuOH. Purification of the EtOACsoluble extract by utilizing normal-phase and reversed-phase column chromatography, followed by reversed-phase HPLC, resulted in the isolation of compounds $\mathbf{1}$ and $\mathbf{2}$.

Compound 1 has the molecular formula of $\mathrm{C}_{15} \mathrm{H}_{24} \mathrm{O}_{4}$, as deduced from the ${ }^{13} \mathrm{C}$ NMR and HRFABMS data, which indicated four degrees of unsaturation. Analysis of ${ }^{1} \mathrm{H},{ }^{13} \mathrm{C}$ and DEPT NMR data (Table 1) revealed the presence two methyls, six methylenes (two oxygenated), three methines, and four quaternary carbon including carbonyl ( $\delta$ 199.8) functionality. These data accounted 21 carbon-bound protons, requiring the presence of three hydroxyl groups in the molecule. In addition, carbon resonances observed at $\delta$ $199.8, \delta 161.6$, and $\delta 124.4$ were strongly suggestive of the presence of an $\alpha, \beta$-unsaturated ketone moiety. Since the above structure information accounted for all but two unsaturation equivalents, compound $\mathbf{1}$ must be bicyclic to satisfy four degrees of unsaturation required by its molecular formula. The structure of remophilanetriol was unambiguously deduced by analysis of 2D NMR data (COSY, HMQC, and $\mathrm{HMBC}$ ). Analysis of COSY results led to the

Table 1. 1D and 2D NMR data for 1 in acetone- $d_{6}$

\begin{tabular}{|c|c|c|c|c|}
\hline no & $\delta_{\mathrm{C}}(\mathrm{mult})^{a}$ & $\delta_{\mathrm{H}}(\text { int, mult, } J \text { in } \mathrm{Hz})^{b}$ & COSY & $\mathrm{HMBC}(\mathrm{H} \rightarrow \mathrm{C})$ \\
\hline 1 & $20.7(\mathrm{t})$ & $\begin{array}{l}1.87(1 \mathrm{H}, \mathrm{m}) \\
1.21(1 \mathrm{H}, \mathrm{m})\end{array}$ & $\mathrm{H}-2, \mathrm{H}-10$ & $\begin{array}{l}\mathrm{C}-2, \mathrm{C}-3, \mathrm{C}-5, \mathrm{C}-10 \\
\mathrm{C}-3, \mathrm{C}-9\end{array}$ \\
\hline 2 & $25.2(\mathrm{t})$ & $\begin{array}{l}1.73(1 \mathrm{H}, \mathrm{m}) \\
1.27(1 \mathrm{H}, \mathrm{m})\end{array}$ & $\mathrm{H}-1, \mathrm{H}-3$ & $\begin{array}{l}\text { C-1, C-3, C-4, C-10 } \\
\text { C- } 1, \text { C-3, C-4, C-10 }\end{array}$ \\
\hline 3 & $30.2(\mathrm{t})$ & $\begin{array}{l}1.41(1 \mathrm{H}, \mathrm{m}) \\
1.23(1 \mathrm{H}, \mathrm{m})\end{array}$ & $\mathrm{H}-2, \mathrm{H}-4$ & $\begin{array}{l}\text { C-1, C-2, C-4, C-5 } \\
\text { C-1, C-2, C-4, C-5 }\end{array}$ \\
\hline 4 & $42.9(\mathrm{~d})$ & $1.53(1 \mathrm{H}, \mathrm{m})$ & H-3, H-15 & C-2, C-3, C-6, C-10, C-14, C-15 \\
\hline 5 & $40.3(\mathrm{~s})$ & - & - & - \\
\hline 6 & $40.1(\mathrm{t})$ & $\begin{array}{c}2.68(1 \mathrm{H}, \mathrm{d}, 18.3) \\
2.22(1 \mathrm{H}, \mathrm{dd}, 18.3,2.8)\end{array}$ & H-8 & $\begin{array}{c}\text { C-1, C-5, C-7, C-8, C-9, C-10, C-11, C-14 } \\
\text { C- } 4, \text { C-5, C-7, C-8, C-9, C-14 }\end{array}$ \\
\hline 7 & $161.6(\mathrm{~s})$ & - & - & - \\
\hline 8 & $124.4(d)$ & $6.10(1 \mathrm{H}, \mathrm{d}, 2.8)$ & $\mathrm{H}-2$ & C-6, C-7, C-10, C-11 \\
\hline 9 & $199.8(\mathrm{~s})$ & - & - & - \\
\hline 10 & 54.7 (d) & $2.14(1 \mathrm{H}, \mathrm{dd}, 12.0,3.7)$ & $\mathrm{H}-1$ & C-1, C-2, C-4, C-9, C-14 \\
\hline 11 & $77.2(\mathrm{~s})$ & - & - & - \\
\hline $12^{c}$ & $65.4(\mathrm{t})$ & $3.67(2 \mathrm{H}, \mathrm{m})$ & - & C-7, C-11 \\
\hline $13^{c}$ & $64.8(\mathrm{t})$ & $3.67(2 \mathrm{H}, \mathrm{m})$ & - & $\mathrm{C}-7, \mathrm{C}-11$ \\
\hline 14 & $10.71(q)$ & $0.71(3 \mathrm{H}, \mathrm{s})$ & - & C-4, C-5, C-10 \\
\hline 15 & $14.6(q)$ & $0.87(3 \mathrm{H}, \mathrm{d}, 6.9)$ & $\mathrm{H}-4$ & C-3, C-4, C-5 \\
\hline
\end{tabular}

${ }^{a}$ Recorded at $125 \mathrm{MHz}$. Carbon multiplicities were determined by DEPT experiments. ${ }^{b}$ Recorded at $500 \mathrm{MHz} .{ }^{c}$ Assignments may be interchanged. 
identification of an isolated spin system corresponding to C10, C-1-C-4, C-15 subunit of structure 1. Further connections of this subunit and remaining elements were revealed by HMBC data (Table 1). HMBC correlations of $\mathrm{H}_{2}-1, \mathrm{H}_{3}-15$, and $\mathrm{H}_{2}-3$ with quaternary carbon $\mathrm{C}-5$ revealed that $\mathrm{C}-10$ and $\mathrm{C}-4$ were joined at $\mathrm{C}-5$, thus constructing cyclohexane unit of compound 1 . The methyl group $\left(\mathrm{CH}_{3}-\right.$ 14) was then attached to $\mathrm{C}-5$ on the basis of $\mathrm{HMBC}$ correlations of $\mathrm{H}_{3}-14$ with $\mathrm{C}-4, \mathrm{C}-5$, and $\mathrm{C}-10$. The remaining connection site of $\mathrm{C}-5$ was occupied by isolated methylene group $\left(\mathrm{CH}_{2}-6\right)$ based on HMBC correlations of $\mathrm{H}-4$ and $\mathrm{H}-10$ with $\mathrm{C}-6$. This connection was also supported by HMBC correlations of $\mathrm{H}_{2}-6$ with $\mathrm{C}-4, \mathrm{C}-5, \mathrm{C}-10$, and C14. Additional HMBC correlations of $\mathrm{H}_{2}-6$ with $\mathrm{C}-7, \mathrm{C}-8$, and $\mathrm{C}-9$ (four-bond $\mathrm{HMBC}$ correlation through double bond) enable to connect C- 6 to C-7 of the $\alpha, \beta$-unsaturated ketone moiety. The other end of the $\alpha, \beta$-unsaturated ketone moiety (i.e., ketone carbonyl carbon C-9) was then connected to $\mathrm{C}-10$ on the basis of numerous HMBC correlations such as $\mathrm{H}-8$ with $\mathrm{C}-10, \mathrm{H}_{2}-1$ with $\mathrm{C}-9$, and $\mathrm{H}-10$ with C-9. At this point, the remaining moieties to be accounted were two oxygenated methylene groups and an oxygenated quaternary carbon, which must be hydroxylated to account required three hydroxyl groups in compound $\mathbf{1}$. The oxygenated quaternary carbon $\mathrm{C}-11 \quad(\delta$ 77.2) was connected to C-7 on the basis of HMBC correlations of $\mathrm{H}_{2}-6$ and $\mathrm{H}-8$ with $\mathrm{C}-11$, and the connection was further extended to $\mathrm{C}-12$ and $\mathrm{C}-13$ by $\mathrm{HMBC}$ correlations of $\mathrm{H}_{2}-12$ and $\mathrm{H}_{2}-13$ with $\mathrm{C}-7$ and $\mathrm{C}-11$. Therefore, the gross structure of remophilanetriol was established as depicted in $\mathbf{1}$.

The relative configuration of remophilanetriol (1) was proposed on the basis of NOESY (Figure 1) data and ${ }^{1} \mathrm{H}-{ }^{1} \mathrm{H}$ coupling constant of H-10. Close inspection of Chem3D energy minimized models for cis- and trans-decalin conformations for remophilanetriol (1) suggested that the compound must adapt trans-decalin stereochemistry to account trans-diaxial coupling constant observed for H-10 $(12.0 \mathrm{~Hz})$. With this conformation, NOESY correlations of $\mathrm{H}_{\mathrm{eq}}-6(\delta 2.68)$ with $\mathrm{H}_{3}-14$ and $\mathrm{H}_{3}-15$ suggested that these protons are all on the same face of the trans-decalin, allowing the complete assignment of the stereochemistry of

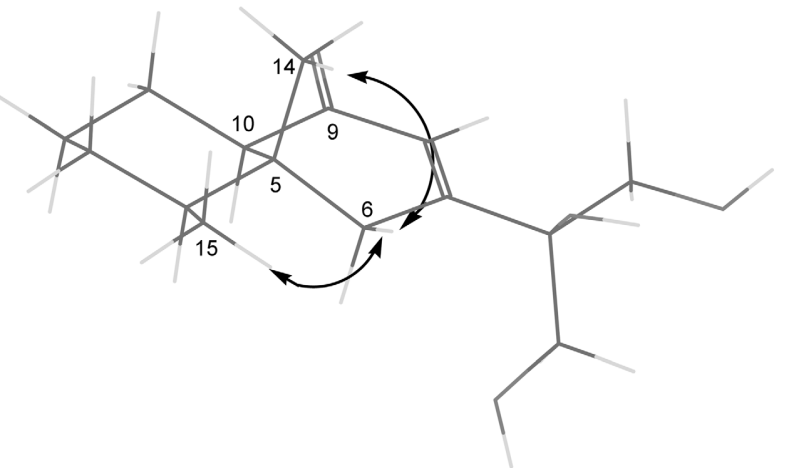

Figure 1. Key NOESY correlations observed in remophilanetriol (1) incorporated in energy-minimized molecular model (Chem3D). remophilanetriol (1). It is also noteworthy that $\mathrm{H}_{\mathrm{eq}}-6(\delta 2.68)$ and $\mathrm{C}-1$ adapted W-type geometry in trans-decalin conformation as depicted in the stereochemistry of $\mathbf{1}$, and thus unusual ${ }^{4} J_{\mathrm{CH}}$ coupling between these groups was observed in the HMBC data. ${ }^{10}$

In addition to remophilanetriol (1), a known norcaroterpenoid-type compound named aeginetic acid (2) was also isolated, and the structure was confirmed on the basis of MS and NMR data comparison with those reported in the literature. $^{9}$

\section{Experimental Section}

General experimental procedures. The optical rotation was recorded on JASCO P-1020 polarimeter. FABMS data were obtained on a JEOL JMS HX-110 spectrometer using PEG and NBA as matrixes. NMR spectra (1D and 2D) were recorded in acetone- $d_{6}$ or MeOH- $d_{4}$ using a JEOL Eclipse$500 \mathrm{MHz}$ spectrometer $\left(500 \mathrm{MHz}\right.$ for ${ }^{1} \mathrm{H}$ and $115 \mathrm{MHz}$ for ${ }^{13} \mathrm{C}$ ), and chemical shifts were referenced relative to the corresponding residual solvents signals (acetone- $d_{6}: \delta 2.04 /$ 29.9, MeOH-- $d_{4}: \delta 3.30 / 49.0$ ). HMQC and HMBC data were optimized for ${ }^{1} J_{\mathrm{CH}}=140 \mathrm{~Hz}$ and ${ }^{\mathrm{n}} J_{\mathrm{CH}}=8 \mathrm{~Hz}$, respectively. Solvents for extractions and open column chromatography were reagent grade and used without further purification. Solvents used for HPLC were analytical grade. Flash column chromatography was carried out using Merck Kieselgel 60 or Aldrich octadecyl-functionalized silica gel (C-18). HPLC separations were performed on an Alltech HS Hyperprep 100 BDS $C_{18}$ column $(1.0 \times 25 \mathrm{~cm}$; $8-\mu \mathrm{m}$ particle size) with a flow rate of $2 \mathrm{~mL} / \mathrm{min}$. Compounds were detected by UV absorption both at 210 $\mathrm{nm}$.

Extraction and isolation. The dried roots of Rehmannia glutinosa were purchased from Kyungdong oriental market. The roots of $R$. glutinosa $(600 \mathrm{~g})$ were crushed and extracted with $\mathrm{MeOH}(5 \mathrm{~L})$ for $24 \mathrm{~h}$. The $\mathrm{MeOH}$ extract was concentrated, suspended in $\mathrm{H}_{2} \mathrm{O}$, and sequentially partitioned with $n$-hexane, EtOAc, and BuOH. A portion $(3.5 \mathrm{~g})$ of the EtOAc-soluble fraction was subjected to silica gel (Merck Kieselgel 60; $0.063-0.2 \mathrm{~mm}$ particle size; $2.5 \times 40 \mathrm{~cm}$ ) column chromatography. The column was eluted with a gradient consisting of mixtures of $n$-hexane- $\mathrm{CH}_{2} \mathrm{Cl}_{2}-\mathrm{MeOH}$ in order of increasing polarity. The fraction $(831 \mathrm{mg})$ eluted with $10 \% \mathrm{MeOH}$ in $\mathrm{CH}_{2} \mathrm{Cl}_{2}$ was further subjected to $\mathrm{C}-18$ flash column chromatography $\left(\mathrm{MeOH}-\mathrm{H}_{2} \mathrm{O}\right.$, stepwise gradient) to afford 10 fractions. The fraction eluted with $30 \% \mathrm{MeOH}$ in $\mathrm{H}_{2} \mathrm{O}$ was finally purified by HPLC using a gradient from 20 to $40 \% \mathrm{CH}_{3} \mathrm{CN}$ in $\mathrm{H}_{2} \mathrm{O}$ over 50 min to yield compound $\mathbf{1}(17.2 \mathrm{mg})$ and $\mathbf{2}(2.5 \mathrm{mg})$.

Remophilanetriol (1): White oily gum; $[\alpha]_{\mathrm{D}}^{25}+3^{\circ}(c$ $0.87, \mathrm{MeOH}) ;{ }^{1} \mathrm{H},{ }^{13} \mathrm{C}$, and $2 \mathrm{D}$ NMR data, Table 1 ; HRFABMS (PEG/NBA matrix) $\mathrm{m} / z 269.1749(\mathrm{M}+\mathrm{H})^{+}$ (calc. for $\mathrm{C}_{15} \mathrm{H}_{25} \mathrm{O}_{4}, 269.1753$ ).

Acknowledgements. Mass spectral data were kindly provided by the Korea Basic Science Institute. 


\section{References}

1. Tang, W.; Eisenbrand, G. Chinese Drugs of Plant Orign; SpringerVerlag: Berlin, Germany, 1992; p 849.

2. Morata, T.; Sasaki, H.; Nishimura, H.; Sugama, K.; Chin, M.; Mitsuhashi, H. Phytochemistry 1989, 28, 2149.

3. Nishsimura, H.; Sasaki, H.; Morata, T.; Chin, M.; Mitsuhashi, H. Phytochemistry 1989, 28, 2705.

4. Morata, T.; Sasaki, H.; Sugama, K.; Sugama, K.; Nishimura, H.; Chin, M.; Mitsuhashi, H. Phytochemistry 1990, 29, 523.

5. Sasaki, H.; Nishimura, H.; Morata, T.; Chin, M.; Mitsuhashi, H.; Komastu, Y.; Maruyama, H.; Guo-rui, T.; Yu-lang, X. Planta Med.
1989, 55,458

6. Sasaki, H.; Nishimura, H.; Chin, M.; Mitsuhashi, H. Phytochemistry 1989, 28, 875 .

7. Morata, T.; Nishimura, H.; Sasaki, H.; Chin, M.; Sugama, K.; Katsuhara, T.; Mitsuhashi, H. Phytochemistry 1989, 28, 2385.

8. Nishimura, H.; Sasaki, H.; Morata, T.; Chin, M.; Mitsuhashi, H. Phytochemistry 1990, 29, 3303.

9. Sasaki, H.; Morata, T.; Nishimura, H.; Ogino, T.; Katsuhara, T.; Sugama, K.; Chin, M.; Mitsuhashi, H. Phytochemistry 1991, 30, 1997.

10. Oh, H.; Gloer, J. B.; Shearer, C. A. J. Nat. Prod. 1999, 62, 497. 